\title{
Autolesão na adolescência sob a perspectiva bioecológica de desenvolvimento humano
}

\author{
Manuela A. da S. Santo' e Débora D. Dell'Aglio', \\ 1 Instituto de Psicologia, Universidade Federal do Rio Grande do Sul (UFRGS) \\ 2 Programa de Pós-Graduação em Educação, Universidade La Salle (Unilasalle)
}

Submissão: 21 abr. 2020.

Aceite: 19 mar. 2021.

Notas das autoras

Manuela A. da S. Santo (D) https://orcid.org/00oo-0003-0127-1331

Débora D. Dell'Aglio (D) https://orcid.org/0ooo-0003-0149-6450

Correspondências referentes a este artigo devem ser enviadas para Manuela A. da S. Santo, Rua Ramiro Barcelos, 2600, Santa Cecília, Porto Alegre, RS, Brasil. CEP 90035-003. E-mail: manuelassanto@gmail.com 


\title{
Resumo
}

Este estudo qualitativo exploratório analisou as características do comportamento autolesivo e da rede de apoio de quatro adolescentes, entre 13 e 17 anos, atendidos em um Centro de Atenção Psicossocial. Os dados foram coletados do prontuário, de uma entrevista semiestruturada e aplicação do Mapa dos Cinco Campos. A partir de uma perspectiva bioecológica, identificaram-se fatores de risco distais: doença mental familiar, histórico de violência intrafamiliar pregressa e ambiente familiar invalidante; fatores de risco intrapessoais: sentimentos de culpa, vergonha, desesperança e vazio; fatores de vulnerabilidade interpessoais: isolamento social e dificuldade de expressão emocional; e fatores estressores: vitimização por pares, conflitos familiares, transição de gênero e morte de familiares. Os fatores de proteção identificados foram os contextos escolar, serviço de saúde e família extensa, além da internet e amizades. Sugere-se que estudos futuros analisem o papel mediador e moderador dos fatores de proteção na autolesão, subsidiando ações de prevenção.

Palavras-chave: autolesão, adolescência, desenvolvimento bioecológico, redes de apoio, saúde mental

\section{SELF-INJURY IN ADOLESCENCE FROM A BIOECOLOGICAL PERSPECTIVE OF HUMAN DEVELOPMENT}

\begin{abstract}
This exploratory qualitative study analyzed the characteristics of the self-injury behavior of four adolescents, between 13 and 17 years sold, served in a Center for Psychosocial Attention and their support networks. Data were collected from the care center records, a semi-structured interview and application of the Map of the Five Fields. From a bioecological perspective, distal risk factors were identified: family mental illness, history of intrafamily violence and invalidating family environment; intrapersonal risk factors: feelings of guilt, shame, hopelessness and emptiness; interpersonal vulnerability factors: social isolation and difficulty of emotional expression; and stressful factors: victimization by peers, conflicts with the family, gender transition and death of family members. The protection factors identified were school, health service and extended family contexts, in addition to the internet and friendships. Future studies can analyze the mediating and moderating role of protective factors in self-injury, subsidizing preventive actions.
\end{abstract}

Keywords: self-injury, adolescence, bioecological development, support networks, mental health

\section{LA AUTOLESIÓN EN LA ADOLESCENCIA DESDE UNA PERSPECTIVA BIOECOLÓGICA DEL DESARROLLO HUMANO}

\section{Resumen}

Este estudio cualitativo exploratorio analizó las características del comportamiento de autolesión y de redes de apoyo de cuatro adolescentes, entre 13 y 17 años, atendidos en un Centro de Atención Psicosocial. Los datos se recogieron de los registros del centro de atención, una entrevista semiestructurada 
y aplicación del Mapa de los Cinco Campos. Desde una perspectiva bioecológica, se identificaron factores de riesgo distales: enfermedades mentales familiares, violencia intrafamiliar y entorno familiar invalidante; factores de riesgo intrapersonal: sentimientos de culpa, vergüenza, desesperanza y vacío; factores de vulnerabilidad interpersonal: aislamiento social y dificultad de expresión emocional; y factores de estrés: bullying, conflictos familiares, transición de género y muerte de parientes. Los factores de protección identificados fueron los contextos escolar, servicio de salud y familia extendida, así como la internet y las amistades. Futuros estudios pueden analizar el papel mediador y moderador de los factores de protección en la autolesión, subvencionando acciones preventivas.

Palabras clave: autolesión, adolescencia, desarrollo bioecológico, redes de apoyo, salud mental 
A adolescência é uma etapa específica do ciclo vital, com características típicas e vivências singulares, durante a qual mudanças biológicas, cognitivas e sociais podem tornar o adolescente um público prioritário para intervenções na área da saúde (Tomé et al., 2015). Isso se justifica na medida em que a necessidade de adaptação perante essas transformações biopsicossociais propicia que o adolescente manifeste comportamentos de risco, isto é, experimente situações e recursos potencialmente prejudiciais à sua saúde (Zappe \& Dell'Aglio, 2016).

Entre os comportamentos de risco, pode-se destacar o comportamento autolesivo, definido como uma forma de prejudicar e/ou agredir o próprio corpo, com objetos ou substâncias, com intuito ou não de morte (Turecki \& Brent, 2016). Um dos maiores desafios encontrados na literatura a respeito da autolesão é diferenciá-la das tentativas de suicídio. Enquanto alguns autores só consideram a autolesão sem a presença de uma intenção suicida, outros abordam esses fenômenos como parte de um mesmo contínuo (que vai desde a ideação autolesiva até o suicídio consumado), de modo que ao diferenciá-los completamente podem-se subestimar os riscos e investir recursos insuficientes de tratamento e prevenção (Turecki \& Brent, 2016). Além disso, estudos na área apontam que, na prática, as tentativas de suicídio e as autolesões são comportamentos que se sobrepõem, uma vez que podem ser apresentados em momentos diferentes ou ao mesmo tempo - e, assim sendo, as autolesões podem ser consideradas um fator de risco consistente para tentativas de suicídio futuras (Giletta et al., 2015; Turecki, \& Brent, 2016).

Ainda, muitos esforços da comunidade científica voltam-se para tentar compreender as principais motivações desse fenômeno (Fonseca et al., 2018). Algumas hipóteses sobre a função que a autolesão exerce na vida do adolescente foram exploradas e descritas por Nock (2009) como: regulação emocional, comunicação/sinalização social, analgesia da dor emocional, autopunição, aprendizagem social e pragmatismo.

Paralelamente, características da história dos adolescentes que apresentam esse comportamento e dos contextos nos quais interagem devem ser observadas. A autolesão em amostras clínicas e não clínicas, por exemplo, pode se manifestar de diferentes maneiras e assumir cursos distintos. Na presença de transtornos mentais, a autolesão pode ter início em idades mais precoces, ocorrer com maior frequência e apresentar lesões de maior gravidade (Tschan et al., 2015). Entretanto, de maneira geral, a maioria dos adolescentes que cometem autolesão apresentam fatores de risco em comum, como situações de maus-tratos na infância, rede de apoio fragilizada, psicopatologias prévias, vitimização por pares, predisposição genética e alta reatividade emocional (Nock, 2009).

Dessa forma, faz-se necessário compreender que é a interação entre esses múltiplos fatores - e não cada um isoladamente - que pode levar à autolesão. Por isso, os comportamentos de risco devem ser avaliados de acordo com o contexto de cada adolescente, considerando suas redes de apoio, principalmente o grupo de pares e família (Tomé et al., 2015). 
Na adolescência, as relações entre pares tornam-se mais significativas, e essas experiências de amizade e companheirismo podem ser consideradas mecanismos de proteção (Tomé et al., 2015; Briggs et al., 2017). Os adolescentes passam a assumir os comportamentos e hábitos dos demais, de forma a sentirem-se integrados e bem-aceitos nesse novo meio (Zappe \& Dell'Aglio, 2016). No entanto, Briggs et al. (2017) apontam que o papel do grupo de pares é, muitas vezes, subestimado no comportamento suicida do adolescente, pois os amigos podem tanto proteger quanto aumentar o risco para o comportamento autolesivo.

Embora na adolescência haja uma tendência natural de aproximação com os pares, a família, como primeiro núcleo de socialização, pode fornecer elementos-chave para o desenvolvimento, por meio do estabelecimento de regras e limites, modelos positivos e instrumentalização para a autonomia (Tomé et al., 2015). Entretanto, o comportamento autolesivo tem sido associado a abordagens parentais mais críticas e hostis, bem como com maiores níveis de estresse entre os pais (Tschan et al., 2015). Além disso, um ambiente invalidante, o contexto familiar marcado por relações que evitam, negam ou rejeitam arbitrariamente as emoções de um indivíduo, pode contribuir para uma maior reatividade emocional e maior suscetibilidade às condutas de autolesão (Crowell et al., 2013).

Ainda que na autolesão os danos físicos fiquem em maior evidência, os aspectos emocionais do adolescente também requerem atenção. Alguns estudos já vêm demonstrando que episódios autolesivos estão comumente associados a sentimentos de solidão, vergonha, autocrítica e culpa (Tschan et al., 2015), e machucar o próprio corpo pode significar uma maneira de aliviar a angústia e lidar com situações aversivas (Turecki \& Brent, 2016). Por isso, é importante compreender não apenas o ato em si, ou os danos físicos causados, mas também os sentimentos subjacentes, os fatores contextuais e fatores precipitantes da vida do adolescente que se autolesiona (Nock, 2009). Dessa forma, em razão da complexidade do fenômeno e das múltiplas variáveis que estão em interação no ato de autolesionar-se, faz-se necessária a utilização de abordagens teóricas que abranjam a dimensão biopsicossocial do adolescente com comportamento de risco.

O modelo bioecológico de desenvolvimento humano (Bronfenbrenner, 2011) permite compreender a interação constante e recíproca do sujeito em desenvolvimento com os sistemas - diretos e indiretos - aos quais pertence. Para tanto, foi proposto o modelo processo-pessoa-contexto-tempo (PPCT). O processo se refere às inter-relações estabelecidas pelas pessoas com as quais um sujeito convive por meio dos sistemas e ao longo do ciclo vital, com interações recíprocas e progressivamente mais complexas. A pessoa é a dimensão que contempla características biopsicossociais de um ser humano, que afetam e são afetadas pelas relações estabelecidas com o ambiente, em todos os níveis dos sistemas. O contexto envolve a multiplicidade de ambientes em que um sujeito está inserido e que podem ser entendidos como microssistema (ambientes imediatos), mesossistema (interação entre os microssiste- 
mas), exossistemas (ambientes em que não se está em contato direto, mas que igualmente influenciam no desenvolvimento) e macrossistema (valores culturais e morais). Finalmente, temos o tempo como dimensão de um contínuo de transformações e constâncias ao longo dos ciclos de vida (Bronfenbrenner, 2011).

Nock (2009) propôs um modelo integrativo teórico, alinhado aos preceitos bioecológicos, que abrange uma complexidade de variáveis de risco, tanto distais quanto proximais, que interagem na conduta autolesiva do adolescente. O autor sugere que o somatório e a relação entre os fatores de risco distais resultam em fatores de vulnerabilidade intra (baixa tolerância ao estresse e emoções e cognições aversivas) e interpessoais (baixa capacidade na resolução de problemas e defasagem em habilidades de comunicação). Tais fatores de vulnerabilidade, por sua vez, resultam em uma baixa tolerância ao estresse que pode levar à autolesão - uma forma mais rápida e eficaz para regular experiências afetivas e situações sociais aversivas (Nock, 2009).

Tanto a teoria bioecológica (Bronfenbrenner, 2011) quanto o modelo integrativo de Nock (2009) demonstram a importância de se estudarem fenômenos, como a autolesão, por meio de uma perspectiva sistêmica, interacionista e relacional. Na autolesão, apesar de os fatores psicológicos e emocionais do indivíduo serem relevantes, é preciso também atentar para a forma como a etapa de desenvolvimento, o contexto social e familiar e as redes de apoio irão impactar o seu curso.

Assim, o objetivo deste estudo foi analisar as características do comportamento autolesivo de quatro adolescentes atendidos em um Centro de Atenção Psicossocial Infantojuvenil (Caps IJ), bem como as características das suas redes de apoio. Este estudo transversal qualitativo exploratório, com delineamento de estudo de casos múltiplos (Yin, 2005), buscou compreender também as características pessoais, familiares e mesossistêmicas dos adolescentes.

\section{Método}

\section{Participantes}

Participaram quatro adolescentes que estavam em atendimento em um Caps IJ da região metropolitana de Porto Alegre, com idades de 13 (Elisa e Júlia), 15 (Paulo) e 17 (Mateus) anos, com famílias monoparentais (Elisa e Mateus), reconstituída (Júlia) e extensa (Paulo). Eles estavam em tratamento no Caps IJ havia três meses (Elisa), seis meses (Paulo), dez meses (Júlia) e 11 meses (Mateus). Destaca-se que, dos quatro participantes, apenas Elisa não estava frequentando a escola no momento em que foram realizadas as entrevistas, e Paulo já havia ficado seis meses em evasão escolar. Os nomes utilizados são fictícios para melhor preservar a identidade dos participantes.

Os critérios para seleção dos participantes foram: ter entre 12 e 18 anos incompletos (conforme definição de adolescência pelo Estatuto da Criança e do Adolescente (ECA), ter 
apresentado pelo menos um episódio de comportamento intencional de autolesão, com ou sem intenção suicida, e estar em atendimento no Caps IJ há, no mínimo, um mês. Excluíram- se os adolescentes que não tinham indicação da equipe técnica para a participação da pesquisa e não aceitassem participar ou que não tivessem autorização do seu responsável legal para participação na pesquisa. A partir das indicações da equipe técnica, foram selecionados por conveniência quatro casos de diferentes sexos, diferentes idades e diferentes configurações familiares, buscando uma diversificação de características na amostra.

\section{Instrumentos}

- Entrevistas com os adolescentes: foi utilizada uma entrevista semiestruturada para investigar os seguintes aspectos: comportamento de autolesão ("O que tu usas para te autolesionar? O que normalmente tu sentes antes de começar a te autolesionar?"), percepções do adolescente quanto à sua família (Com quem tu moras e como é a tua relação com essas pessoas? Com qual pessoa da tua família tu te sentes mais seguro para falar quando tens algum problema?"), uso da internet ("Tu já usaste a internet alguma vez para buscar conteúdos relacionados à autolesão?"), influência dos pares ("Antes de te ter machucado a primeira vez, tu já havias visto isso em algum lugar ou alguém fazendo?"), papel da escola no comportamento de autolesão ("Fala sobre situações positivas e negativas que já vivenciaste na escola? Quais pessoas da escola costumam te ajudar quando tens algum problema?"), percepção sobre o tratamento em saúde mental ("Tu percebes alguma diferença de como estavas te sentindo quando chegaste a esse serviço? Que tipo de ajuda tu recebes?") e perspectiva de futuro ("Quais coisas tu gostarias de modificar ou conservar em ti ou na tua vida? Como te imaginas no futuro?").

- Prontuários: foram utilizados para coletar dados sociodemográficos dos adolescentes, como idade e escolaridade, e dados sobre a família de origem (transtorno mental, configuração, moradores da casa), seu comportamento e a história de atendimento na instituição (avaliação psiquiátrica, medicações, internações prévias, outros atendimentos no serviço).

- Mapa dos Cinco Campos: instrumento lúdico adaptado para o Brasil por Hoppe (1998), para avaliar a estrutura e a função da rede de apoio social. O Mapa dos Cinco Campos é constituído por um pano de feltro com seis círculos concêntricos, divididos em campos, e figuras que podem ser fixadas por meio de velcro. As figuras representam adultos, adolescentes e crianças e devem ser dispostas pelo participante de acordo com a proximidade e com o campo do qual essa pessoa faz parte: família, Caps IJ, amigos e parentes, contatos formais e escola. Neste estu- 
do, o Mapa dos Cinco Campos foi utilizado de forma complementar à entrevista, buscando mais dados sobre a qualidade e a quantidade de vínculos na rede de apoio de cada participante.

\section{Procedimentos e considerações éticas}

Foram identificados 139 prontuários de pacientes ativos e inativos no serviço com histórico de comportamento autolesivo, analisados em um estudo quantitativo anterior. A partir dessa amostra, foi solicitado aos profissionais do Caps IJ que fizessem a indicação de adolescentes que estivessem em atendimento no serviço no momento da pesquisa e cumprissem os critérios de inclusão do estudo. A pesquisa foi autorizada pela instituição, e os profissionais indicaram sete adolescentes, dos quais cinco foram contatados e quatro aceitaram participar da pesquisa.

O estudo seguiu orientações para pesquisas com seres humanos, de acordo com a Resolução no 510 do Conselho Nacional de Saúde e com os artigos previstos pelo ECA (1990). Para tanto, o projeto de pesquisa foi submetido ao Comitê de Ética em Pesquisa da universidade, aprovado sob o Parecer $n^{0} 3.202 .582$.

Os responsáveis que concordaram com a participação do adolescente assinaram um Termo de Consentimento Livre e Esclarecido, e o respectivo adolescente, um Termo de Assentimento. Realizaram-se dois encontros com cada participante, sendo o primeiro para a entrevista e o segundo para a aplicação do Mapa dos Cinco Campos, com tempo de duração média de 40 e 35 minutos, respectivamente. Os encontros foram agendados previamente, de acordo com a disponibilidade dos adolescentes e cuidadores e realizados individualmente em ambiente reservado dentro da própria instituição. As entrevistas foram gravadas, transcritas integralmente e posteriormente analisadas.

\section{Análise dos dados}

As entrevistas, após transcritas, foram submetidas à análise de conteúdo. Conforme sugerido por Bardin (2011), a análise seguiu três principais etapas. Na primeira etapa, de pré-análise, realizaram-se a leitura das transcrições e a organização dos dados das entrevistas e do Mapa dos Cinco Campos. Após isso, na etapa de exploração do material, definiram-se os sistemas de codificação, classificação e categorização das unidades de registro do material coletado, a partir das quatro dimensões do modelo PPCT - processo, pessoa, contexto e tempo (Bronfenbrenner, 2011). Finalmente, na etapa de tratamento dos resultados, discutiram-se os dados em três eixos principais, definidos a priori, que agruparam as dimensões do modelo PPCT: 1. características do comportamento autolesivo (pessoa); 2 . características da família e rede de apoio percebida (contexto e processos proximais); e 3. perspectivas de futuro (tempo), a partir da literatura disponível sobre autolesão, da teoria bioecológica (Bronfenbrenner, 2011) 
e do modelo teórico integrativo de Nock (2009). A organização dos resultados no modelo PPCT e a posterior discussão desses nos eixos de análise foram realizadas a partir de consenso entre as pesquisadoras, procurando observar tanto características protetivas como de risco presentes nos casos.

O Mapa dos Cinco Campos foi aplicado em três dos adolescentes participantes, uma vez que uma adolescente não compareceu ao segundo encontro marcado. Para este estudo, os cinco campos foram nomeados de família, Caps IJ, amigos, contatos formais e escola. Realizaram-se registros escritos da aplicação, conforme protocolo do instrumento, e também houve registro de áudio. Os dados desse instrumento foram analisados qualitativamente, observando a quantidade de pessoas nos campos e o nível de proximidade percebido pelos adolescentes. Tais dados foram relatados nas dimensões "processo" e "contexto" na seção "Resultados" e, posteriormente, discutidos em conjunto com os demais dados das entrevistas nos três eixos de análise. Por fim, realizou-se o processo de triangulação de dados (Yin, 2005) advindos dos prontuários dos participantes, das entrevistas realizadas e dos resultados do Mapa dos Cinco Campos, objetivando maior validade na pesquisa.

\section{Resultados}

Os resultados da análise de dados dos quatro participantes do estudo são apresentados de forma conjunta, descrevendo características pessoais e autolesivas dos adolescentes na categoria pessoa; características dos seus relacionamentos e processos proximais na categoria processos; características dos seus contextos de inserção, destacando-se a família, escola, amigos e a internet, na categoria contextos; e aspectos de seu passado, presente e futuro, na categoria tempo. Após a apresentação dos principais resultados, a Tabela 1 exemplifica, com falas dos participantes, as categorias do modelo PPCT e os respectivos eixos de análise da discussão.

\section{Pessoa}

Elisa, Paulo, Mateus e Júlia são adolescentes que chegaram ao serviço por apresentarem comportamento autolesivo. Todos os adolescentes passaram por uma avaliação psiquiátrica e estavam em uso de medicações, e as duas meninas vieram logo após um período de internação psiquiátrica de curta duração. Conforme constava nos prontuários individuais, apenas Elisa não tinha uma hipótese diagnóstica psiquiátrica, ao passo que os demais tinham hipóteses diagnósticas de transtorno de humor bipolar, episódio depressivo maior e transtorno de humor bipolar. Mateus e Júlia referiram ter orientação sexual heteronormativa, ao passo que Elisa se disse bissexual e Paulo apresentou-se como um menino transgênero homossexual. Na Tabela 1, são apresentadas características do comportamento autolesivo dos participantes. 


\section{Tabela 1}

Características do comportamento autolesivo dos participantes

\begin{tabular}{|c|c|c|c|c|}
\hline & Elisa & Paulo & Mateus & Júlia \\
\hline Tipo de autolesão & $\begin{array}{l}\text { Cortes na pele e } \\
\text { hiperdosagem de } \\
\text { medicação. }\end{array}$ & $\begin{array}{l}\text { Cortes na pele } \\
\text { arranhões e } \\
\text { enforcamento. }\end{array}$ & Cortes na pele. & Cortes na pele. \\
\hline Objeto utilizado & $\begin{array}{l}\text { Faca, lâminas } \\
\text { de barbear, } \\
\text { apontador e } \\
\text { pedaços de } \\
\text { espelho. }\end{array}$ & $\begin{array}{l}\text { Faca, lâminas } \\
\text { de barbear, } \\
\text { apontador e } \\
\text { tesoura. }\end{array}$ & $\begin{array}{l}\text { Faca, lâminas } \\
\text { de barbear e } \\
\text { apontador. }\end{array}$ & $\begin{array}{l}\text { Faca, lâminas } \\
\text { de barbear e } \\
\text { apontador. }\end{array}$ \\
\hline $\begin{array}{l}\text { Partes do } \\
\text { corpo atingidas }\end{array}$ & $\begin{array}{l}\text { Antebraço } \\
\text { e barriga. }\end{array}$ & $\begin{array}{l}\text { Antebraço, } \\
\text { coxas e seios. }\end{array}$ & $\begin{array}{l}\text { Antebraço } \\
\text { e mão. }\end{array}$ & $\begin{array}{l}\text { Antebraço } \\
\text { e barriga. }\end{array}$ \\
\hline $\begin{array}{l}\text { Sentimentos } \\
\text { associados à autolesão }\end{array}$ & Desamparo. & Vergonha e culpa. & Desamparo. & Vergonha. \\
\hline
\end{tabular}

Sobre as autolesões, elas começaram há cerca de dois anos para Elisa e Paulo e há um ano para Mateus e Júlia. O tempo entre o início das autolesões até o momento em que chegaram para tratamento de saúde mental foi em média 9,5 meses - o menor tempo foi de Júlia (três meses) e o maior de Elisa (um ano e meio).

Quando questionados sobre os critérios de escolha das regiões do corpo, todos eles responderam ter dois critérios básicos: 1 . a facilidade de esconder os machucados e 2. a sensibilidade à dor na região. Os adolescentes referiram que as autoagressões iniciaram de forma mais espaçada e superficial, como um "treinamento" no caso de Mateus, e foram aumentando progressivamente de frequência (chegando a ocorrer duas vezes ao dia, no caso de Júlia) e gravidade (necessitando de cuidados médicos). Todos os adolescentes realizavam as autolesões dentro de casa, preferencialmente no quarto e banheiro.

Houve divergências quanto à forma de início das autolesões, de modo que Paulo e Júlia pensaram sobre as autolesões por alguns meses antes de iniciarem esse comportamento, e Mateus e Elisa cometeram-nas de maneira impulsiva, sem planejamento prévio. Os quatro adolescentes relatam também a ocorrência de isolamento social (deixar de ir à escola, faltar às reuniões familiares, permanecer no quarto por mais tempo), seja pela intenção de ocultar as lesões ou pela ideia de que não seriam compreendidos.

Nos quatro adolescentes, as autolesões advinham de uma tristeza intensa e, depois, geraram alívio psicológico. Sobre a intenção suicida, todos os adolescentes responderam que o desejo de morte variou ao longo do tempo, mostrando-se presente em algumas vezes, mas não em todas. Mesmo quando presente, o sentimento em relação à morte sempre se mostrou ambivalente, visto que os adolescentes afirmaram que, após terem iniciado as tentativas de suicídio, desistiram no meio das lesões e/ou buscaram ajuda em seguida. 
A ideação suicida também variou de acordo com o tipo de método utilizado. Para Paulo, a vez em que tentou sufocar-se foi quando tinha maior clareza sobre sua intenção suicida. Da mesma forma, Elisa ingeriu uma quantidade tóxica de medicações quando teve a intenção de suicidar-se. Esses adolescentes não sabem apontar a diferença da ideação suicida desses episódios para os outros em que utilizaram objetos perfurocortantes, pois disseram que também já haviam tentado morrer com esses últimos. Sobretudo, eles referem que, quando na utilização de métodos alternativos - e, aparentemente, mais letais -, o desejo de morrer parecia mais claro.

\section{Processo}

Os processos proximais identificados nos participantes atuaram como fatores precipitantes das autolesões e também como fatores de proteção perante o adoecimento mental. Foram os vínculos com as pessoas nos seus mais diversos sistemas que influenciaram a forma como os adolescentes se relacionavam com as autolesões.

As relações familiares foram, algumas vezes, marcadas por experiências violentas em termos psicológicos (Júlia e Paulo), físicos (Paulo) e sexuais (Elisa). Para os adolescentes, as relações familiares eram invalidantes (Paulo e Júlia) e distantes (Mateus). Ainda que considere ter uma boa relação com seu pai, Mateus diz que esse sempre foi "fechado" e não lembra se alguma vez o percebeu triste ou chorando. Elisa, por sua vez, sente que sempre teve sua privacidade "invadida" e foi envolvida, repetidamente, nas brigas conjugais dos seus pais já divorciados. Paulo conta que, quando suas autolesões foram descobertas, isso foi exposto em um jantar de família, causando-Ihe um imenso constrangimento e decepção. Todos os participantes ressaltam, sobretudo, um sentimento de invisibilidade: consideram que, de formas diferentes, tiveram sua identidade, privacidade e emoções negadas diante da família.

Em contrapartida, nos momentos de maior vulnerabilidade emocional, os adolescentes puderam contar com outras pessoas da família que Ihes ofereceram conforto e acolhimento em tempos difíceis. Júlia e Elisa citam as avós maternas como pessoas de sua confiança e afeto, enquanto para Paulo foi a sua irmã, sendo ela o único membro da família que o apoiou na sua transição de gênero e o incentivou na busca da sua identidade.

Evidenciaram-se também relações de risco e de proteção no contexto escolar. Júlia e Elisa citaram situações de bullying que já viveram no passado, ao passo que Paulo ainda as vive nos dias de hoje. Contudo, foi também nesse contexto que encontraram mais apoio. Elisa relata, por exemplo, que se sentiu amparada pelo seu professor de português quando este a surpreendeu revelando dificuldades pessoais que também já havia vivido. Por sua vez, Paulo reforça que se afastou de todos na escola porque tinha conviç̧ão de que ninguém entenderia o que ele estava vivendo. 
O protagonismo dos amigos também se mostrou presente no relato dos participantes. Muitos dos pares foram as primeiras pessoas a saber da existência das autolesões, como nos casos de Elisa e Mateus. Para Elisa, inclusive, foi uma amiga, já em tratamento psicológico, que a encorajou a buscar atendimento no Caps IJ. Ela valoriza esse apoio e diz que é uma forma de atenuar seu sentimento de solidão. Ademais, Mateus considera que são poucas as pessoas da sua idade que conseguem compreender o que significa um adoecimento mental: ele percebe que perdeu amizades devido às suas dificuldades emocionais.

Entretanto, os amigos foram as principais influências para o engajamento nesse tipo de comportamento, visto que todos os participantes conheceram previamente algum colega ou amigo próximo que já havia se autolesionado ou cometido suicídio. Júlia diz lembrar-se de uma colega que sempre aparecia com muitas marcas de cortes nos punhos. Ainda que não entendesse na época, quando passou a cogitar as autolesões se lembrou da menina e, de imediato, pensou que, se havia funcionado com a amiga, poderia funcionar com ela também. Mateus teve uma colega que cometeu suicídio e lamenta, com pesar, o fato de ela não ter recebido ajuda a tempo.

O Mapa dos Cinco Campos possibilitou observar a distribuição, nos diferentes contextos, das relações mencionadas pelos adolescentes e qualificá-las quanto à sua proximidade ou ao seu distanciamento. Denominaram-se os sistemas de "família", "parentes", "amigos" e "escola", e nomeou-se o último como "contatos formais", que incluiu serviços como o Caps IJ, a Igreja e o grupo de música e de esporte.

Para Júlia, as pessoas de sua família extensa foram as únicas que ocuparam o nível 1 (maior proximidade) do seu mapa, ao passo que as pessoas de sua família nuclear ocuparam o terceiro e quarto níveis, e seu pai foi citado como uma relação rompida. No campo "contatos formais", Júlia citou sua técnica de referência do Caps IJ, que a atende sistematicamente, e com quem diz ter uma relação de confiança e reciprocidade. Já nos campos escola e amigos, Júlia representou relações próximas e numerosas. Sua tia materna foi aquela apontada como a pessoa que a ajuda em momentos críticos.

Para Mateus, o nível 1 foi ocupado em todos os contextos, e o adolescente referiu percepção positiva de rede de apoio. No contexto dos amigos, incluiu os virtuais e os da infância. Nas relações conflituosas, foram incluídos sua ex-namorada e um amigo que possuía na época em que adoeceu, pois diz que ele não era "boa companhia". Ainda que tenha anteriormente citado seu pai como uma pessoa distante, situou-o no primeiro nível do contexto familiar e o apontou como a pessoa que mais o ajuda quando precisa.

No caso de Paulo, o campo "parentes" foi o mais representado no nível 1, com cinco pessoas. Todavia, na "família" as pessoas foram colocadas nos níveis 4 e 5 , tendo as relações com a mãe e o pai identificadas como rompimentos. Os amigos mostraram-se próximos de Paulo no mapa, mas foi a sua irmã a principal fonte de apoio percebida. 


\section{Contexto}

Ainda que considerem solitário o fenômeno da autolesão, os adolescentes sempre estiveram inseridos em contextos que parecem ter contribuído, direta ou indiretamente, para o funcionamento dessa conduta. Família, escola, serviços de saúde e internet foram os principais sistemas mencionados pelos participantes.

De acordo com Paulo e Júlia, embora a família nuclear não tenha sido protetiva em muitos momentos, a família extensa mostrou-se um microssistema satisfatório. Eles afirmaram que costumam se sentir mais amparados pelos parentes com que não convivem diariamente do que por aqueles com quem dividem ou já dividiram a mesma casa. Os quatro adolescentes citaram desentendimentos frequentes no contexto familiar que eram, muitas vezes, desencadeadores de episódios de autolesão. Ainda que considerem importante possuir uma família, nem sempre se sentem protegidos por ela.

Quanto à escola, com exceção de Elisa que estava em evasão escolar e percebia esse lugar como hostil e Paulo que sofria situações de bullying, os outros dois participantes falam da escola como um lugar positivo e "acolhedor". De forma geral, é mencionada como um espaço importante para a socialização, para o compartilhamento de experiências e histórias, e pelas relações de apoio que se estabelecem. Por vezes, entretanto, a escola reproduz relações competitivas e em desequilíbrio de poder, o que afeta diretamente a saúde mental dos alunos, segundo os adolescentes.

Enquanto a família e os amigos representam os principais microssistemas na vida de um adolescente, a internet é, provavelmente, um dos protagonistas atuais do mesmo sistema, já que é nesse espaço que ocorrem muitas relações e formação de processos proximais. Os participantes denominaram a internet de uma "realidade paralela", em que podem buscar informações complementares às suas experiências cotidianas, embora o seu papel tenha divergido entre eles. Para Paulo, as informações on-line podem piorar sintomas depressivos e fomentar comportamentos mais autodestrutivos. Por sua vez, Júlia, Mateus e Elisa ponderam sobre os aspectos positivos desse meio: possibilidade de expressar sentimentos que, nas relações face a face, não conseguem ser ditos, aumento da rede de apoio, orientações sobre onde buscar ajuda, informações sobre autocuidado e cuidados caseiros referentes às autolesões e identificação com histórias semelhantes.

Foi por meio de uma amiga virtual, inclusive, que Elisa soube da existência do Caps IJ no município. Para os outros participantes, o fluxo na rede ocorreu de forma diferente: Paulo veio transferido de um Caps IJ do município onde morava com o pai, ao passo que Júlia e Mateus foram encaminhados pelo Pronto Atendimento Municipal. Ainda que tenham vindo de trajetórias diferentes na rede intersetorial, os quatro adolescentes concordam em um aspecto: o Caps IJ se tornou um espaço de reestruturação pessoal. Paulo diz que ali encontrou um lugar para dar vazão a todas as suas emoções. Da mesma forma, Júlia diz que encontrou acolhimen- 
to no Caps IJ num momento em que não era acolhida nem pela própria família. Diferentemente do que imaginava, ela disse que receber um diagnóstico de transtorno mental foi libertador e fundamental para que seu sofrimento fosse validado. Por conta disso, Mateus e Elisa se sentem mais seguros e motivados para fazer novos planos. Eles não veem o Caps IJ como um lugar de adoecimento, mas de resgate da sua saúde e potencialidade. O posto de saúde do território dos participantes e a internação psiquiátrica vivenciada por Elisa e Júlia também foram mencionados como espaços de cuidado, porém de menor proximidade.

\section{Tempo}

A dimensão do tempo pode ser avaliada em vários assuntos abordados pelos adolescentes durante a entrevista. Quando se remeteram ao passado, os adolescentes não se lembravam de algum momento pregresso em que se sentiam saudáveis emocionalmente. Todos falam da infância como um período de intensas dificuldades enfrentadas, como os episódios de violência psicológica descritos por Paulo e de alienação parental vivenciada por Júlia. Júlia, inclusive, fala que nunca pôde registrar o nome do pai em sua documentação, pois sua mãe não queria que tivessem contato. Assim, identificou-se que a vulnerabilidade emocional sempre acompanhou os adolescentes ao longo do desenvolvimento, o que foi agravado por eventos estressores. Quanto ao macrotempo, também foram observados aspectos transgeracionais na história dos participantes, como no caso de Elisa que mencionou ter presenciado um episódio de autolesão da irmã mais velha, e do histórico de transtornos mentais na família nuclear de Mateus (mãe e irmão).

Os participantes percebem mudanças que foram ocorrendo ao longo dos anos, algumas de forma gradual e outras de forma abrupta - como é o caso da perda de familiares próximos para Júlia e Mateus. Eles falam de habilidades que possuíam e que perderam, como no caso de Júlia que era uma aluna com um ótimo desempenho e hoje tem tido dificuldades escolares.

No caso de Paulo, entretanto, essas transformações foram mais intensas: há três anos iniciou uma transição de gênero quando percebeu que não se reconhecia mais e tampouco se sentia confortável no corpo de uma mulher. Foi um processo que durou seis meses, pois Paulo reconhece que demorou a aceitar que não havia nada de errado com ele. Foi uma mudança para si e para os outros: seus familiares e colegas também tiveram dificuldade de se adaptar ao seu novo nome e à sua nova aparência. Paulo conta que alguns episódios autolesivos estiveram relacionados com essa transição, mas não pelo fato de rejeitar sua nova identidade: seu sofrimento era por não ser reconhecido da forma como gostaria de ser visto pelos demais. 
Quando questionados sobre o que gostariam que permanecesse igual na vida deles, os adolescentes respondem que desejam manter suas potencialidades, como o senso de humor citado por Mateus e a dedicação aos estudos citada por Paulo. Além disso, eles citam também o desejo de seguir buscando o seu bem-estar pessoal e de manter intactas algumas lembranças felizes que têm das suas infâncias.

Os quatro adolescentes exprimiram um desejo positivo de futuro, com expectativas de conquistas profissionais, amadurecimento emocional e uma saúde mental satisfatória. Apresentam desejo de ter uma família própria, na qual consigam estabelecer relações mais saudáveis e fortalecidas. Desejam, sobretudo, ter futuro: sabem que, quando não o veem, não quer dizer que ele não exista, mas sim que apenas não o percebem naquele momento.

Na Tabela 2, são apresentadas algumas falas dos participantes que foram analisadas dentro das quatro categorias do modelo PPCT e nos três eixos de análise utilizados na discussão. As verbalizações foram selecionadas a fim de exemplificar as características de proteção e risco observadas nas categorias.

\section{Discussão}

\section{Características do comportamento autolesivo (pessoa)}

Este estudo analisou as características da rede de apoio e do comportamento autolesivo de adolescentes atendidos pelo Caps IJ, na região metropolitana de Porto Alegre. Quanto às características identificadas na autolesão, os quatro adolescentes deste estudo utilizaram no mínimo um e no máximo três métodos de autolesão, com múltiplos episódios, e demoraram, em média, nove meses e meio para chegar a um serviço de saúde. Esses dados indicam um comportamento com indicadores clínicos de gravidade, devido à variabilidade de métodos e frequência com que aconteceram (Ammerman et al., 2019).

Sobre as principais funções assumidas pelas autolesões relatadas pelos adolescentes, a regulação emocional e a autopunição se destacam. A regulação emocional pode ser observada quando o comportamento autolesivo é utilizado para amenizar estados cognitivos e emocionais intensos e negativos, como também para incitar emoções positivas, como o alívio (Fonseca et al., 2018). Já a autopunição aparece mais ligada a um estado autodepreciativo e autocrítico (Nock, 2009). Embora tenham sido identificados eventos estressores do ambiente que parecem ter precipitado o início do comportamento, os participantes também relataram estados emocionais internos, tais como solidão, vergonha, culpa e desamparo que motivaram a busca pelas autoagressões.

O sentimento de solidão, nesse cenário, foi uma vulnerabilidade interpessoal mencionada por todos os participantes. A revisão de literatura realizada por Calati et al. (2019) apontou o isolamento social como um dos principais fatores associados ao comportamento suicidário na adolescência, sendo definido não só pelo número de contatos, mas também pela 


\section{Tabela 2}

Falas dos participantes inseridas nas categorias do modelo PPCT e nos eixos de análise posteriores

\begin{tabular}{|c|c|c|c|c|c|}
\hline $\begin{array}{c}\text { Eixos } \\
\text { de análise }\end{array}$ & $\begin{array}{c}\text { Modelo } \\
\text { PPCT }\end{array}$ & Elisa & Paulo & Mateus & Júlia \\
\hline $\begin{array}{l}\text { Características } \\
\text { do compor- } \\
\text { tamento } \\
\text { autolesivo }\end{array}$ & Pessoa & $\begin{array}{l}\text { "Começou de repente. Pra } \\
\text { falar a verdade, eu não sei te } \\
\text { dizer quando eu decidi fazer. } \\
\text { Eu tava me sentindo mal há } \\
\text { dias já. Um dia eu acordei de } \\
\text { madrugada, fui no banheiro e } \\
\text { comecei a me cortar." }\end{array}$ & $\begin{array}{l}\text { "Pensei bastante sobre o assunto, } \\
\text { porque eu já tinha ouvido que } \\
\text { depois que tu começa não para } \\
\text { mais. Juntei lâminas por dois meses } \\
\text { até que eu criasse coragem... Eu } \\
\text { costumo me sentir muito } \\
\text { decepcionado comigo mesmo por } \\
\text { não ter conseguido evitar. Me } \\
\text { arrependo no segundo seguinte, } \\
\text { mas também me sinto aliviado." }\end{array}$ & $\begin{array}{l}\text { "Eu sentia dor na hora que } \\
\text { cortava. Eu fazia pra sentir } \\
\text { dor, eu queria sentir dor. Por- } \\
\text { que eu só sentia dor } \\
\text { emocional, daí eu queria } \\
\text { sentir dor física." }\end{array}$ & $\begin{array}{l}\text { "No começo eu cortava } \\
\text { porque queria sentir dor, } \\
\text { depois era porque eu queria } \\
\text { morrer. Quando foi } \\
\text { aumentando meus cortes, } \\
\text { eu já tava querendo morrer. } \\
\text { Eu sinto uma sensação } \\
\text { forte, começo a sentir um } \\
\text { vazio, me dá uma tristeza } \\
\text { bem forte e penso que nada } \\
\text { vai dar certo." }\end{array}$ \\
\hline \multirow[t]{3}{*}{$\begin{array}{l}\text { Características } \\
\text { da } \\
\text { família e rede } \\
\text { de apoio } \\
\text { percebida }\end{array}$} & Processo & $\begin{array}{l}\text { "Talvez a minha mãe seja a } \\
\text { pessoa mais próxima, mas ela } \\
\text { quase nunca respeita o meu } \\
\text { espaço. Com o meu pai eu } \\
\text { não tô tendo contato com por } \\
\text { causa da medida protetiva." }\end{array}$ & $\begin{array}{l}\text { "Meu pai dizia que ninguém da } \\
\text { minha família me amava e ele } \\
\text { tinha razão." }\end{array}$ & $\begin{array}{l}\text { "Não consigo falar muito com } \\
\text { meu pai, não fala muito sobre } \\
\text { as minhas emoções, porque } \\
\text { ele é um cara reservado que } \\
\text { não sabe falar sobre essas } \\
\text { coisas. A gente tem tipo uma } \\
\text { relação formal." }\end{array}$ & $\begin{array}{l}\text { "A primeira pessoa que eu } \\
\text { contei quando eu comecei a } \\
\text { me cortar foi a minha tia. } \\
\text { Ela disse que entendia pelo } \\
\text { que eu tava passando. A } \\
\text { minha mãe, quando soube, } \\
\text { simplesmente ignorou." }\end{array}$ \\
\hline & & $\begin{array}{l}\text { "Uma amiga viu os últimos } \\
\text { cortes e ofereceu ajuda, disse } \\
\text { que poderia contar com ela se } \\
\text { eu precisasse de ajuda. Isso } \\
\text { foi importante pra mim." }\end{array}$ & $\begin{array}{l}\text { "Eu tinha muitos amigos e } \\
\text { conversava com eles sobre isso. Eu } \\
\text { me sentia aliviada porque pelo } \\
\text { menos alguém sabia do que eu } \\
\text { tava passando. Eles me apoiavam e } \\
\text { me aconselhavam." }\end{array}$ & $\begin{array}{l}\text { "Perdi a maioria dos } \\
\text { meus amigos. } \\
\text { Eu fui me afastando por } \\
\text { causa da depressão, mas eu } \\
\text { tinha muitos amigos." }\end{array}$ & $\begin{array}{l}\text { "Eu confio muito na minha } \\
\text { tia, na minha avó, em duas } \\
\text { amigas minhas e no meu } \\
\text { namorado. Eu confio muito } \\
\text { neles e sei que sempre vão } \\
\text { me ajudar." }\end{array}$ \\
\hline & Contexto & $\begin{array}{l}\text { "Nem sempre me senti bem } \\
\text { na escola. Sempre } \\
\text { inventavam coisas de mim. } \\
\text { Eu me cortava bastante lá, } \\
\text { porque eu achava que } \\
\text { ninguém se } \\
\text { importava comigo." }\end{array}$ & $\begin{array}{l}\text { "Tudo é competição na escola. Tu } \\
\text { acaba se matando pra fazer um } \\
\text { trabalho, uma prova, sendo que } \\
\text { isso não vai te definir. Às vezes tu } \\
\text { tem um baita potencial, mas vai } \\
\text { mal na prova." }\end{array}$ & $\begin{array}{l}\text { "As coisas positivas da escola } \\
\text { são os amigos, a comida. Fora } \\
\text { que lá a gente conhece } \\
\text { bastante coisa, outras } \\
\text { pessoas, outras histórias..." }\end{array}$ & $\begin{array}{l}\text { "A escola é um lugar pra } \\
\text { construir meu futuro, } \\
\text { mesmo quando eu nem sei } \\
\text { se quero ter futuro." }\end{array}$ \\
\hline
\end{tabular}




\begin{tabular}{|c|c|c|c|c|c|}
\hline $\begin{array}{c}\text { Eixos } \\
\text { de análise }\end{array}$ & $\begin{array}{l}\text { Modelo } \\
\text { PPCT }\end{array}$ & Elisa & Paulo & Mateus & Júlia \\
\hline & & $\begin{array}{l}\text { "Quando eu vim pra cá, eu } \\
\text { tava me sentindo muito, } \\
\text { muito mal. Agora estou } \\
\text { melhor, não sinto mais } \\
\text { vontade de me matar e me } \\
\text { cortar. Eu venho percebendo } \\
\text { que a vida tem } \\
\text { algum sentido." }\end{array}$ & $\begin{array}{l}\text { "Sentir demais, do jeito que eu } \\
\text { faço, é muito ruim e aqui no Caps } \\
\text { eu consigo colocar pra fora sem } \\
\text { explodir por dentro." }\end{array}$ & $\begin{array}{l}\text { "Quando cheguei no Caps, eu } \\
\text { não saía de casa, não via sen- } \\
\text { tido em nada. Aí eu iniciei as } \\
\text { medicações e senti como se } \\
\text { estivesse me } \\
\text { reequilibrando de novo." }\end{array}$ & $\begin{array}{l}\text { "Foi ali quando a psiquiatra } \\
\text { me deu um diagnóstico que } \\
\text { a minha mãe entendeu que } \\
\text { o que eu tinha era real." }\end{array}$ \\
\hline & & $\begin{array}{l}\text { "Já li coisas sobre a autolesão } \\
\text { na internet. Quando eu leio, } \\
\text { eu me identifico muito } \\
\text { porque é exatamente o que } \\
\text { eu passo." }\end{array}$ & $\begin{array}{l}\text { "Ali na internet eu encontro } \\
\text { histórias tão ou mais tristes como a } \\
\text { minha... me sinto péssimo." }\end{array}$ & $\begin{array}{l}\text { "Eu tinha muitos amigos } \\
\text { virtuais, desabafava com eles. } \\
\text { Eu achava mais fácil colocar } \\
\text { para fora o que eu sentia pros } \\
\text { meus amigos da internet do } \\
\text { que pessoalmente." }\end{array}$ & $\begin{array}{l}\text { "Eu comecei a ver uns } \\
\text { vídeos que eles encenam } \\
\text { uma pessoa com depressão } \\
\text { e eu me surpreendi que a } \\
\text { pessoa sentia tudo que } \\
\text { eu sentia." }\end{array}$ \\
\hline $\begin{array}{l}\text { Perspectivas } \\
\text { de futuro }\end{array}$ & Tempo & $\begin{array}{l}\text { "Às vezes penso no futuro e } \\
\text { fico feliz. Eu quero ser } \\
\text { psicóloga, policial ou } \\
\text { veterinária. Fico pensando no } \\
\text { que eu preciso estudar pra ser } \\
\text { uma dessas coisas." }\end{array}$ & $\begin{array}{l}\text { "Me imagino saudável, fazendo } \\
\text { faculdade, tendo a minha casa, e } \\
\text { lidando com os problemas de uma } \\
\text { forma melhor. Às vezes não me } \\
\text { vejo no futuro, mas às vezes eu } \\
\text { consigo ver que todos os } \\
\text { empecilhos que existem na minha } \\
\text { vida são problemas psicológicos } \\
\text { que eu tenho, e isso pode ser } \\
\text { revertido. Então não é como se eu } \\
\text { não fosse ter futuro, é só como se } \\
\text { eu não conseguisse enxergar." }\end{array}$ & $\begin{array}{l}\text { "Minha alegria, senso de } \\
\text { diversão, queria que essas } \\
\text { coisas não mudassem. } \\
\text { Eu sinto que tenho muita } \\
\text { coisa pra viver ainda." }\end{array}$ & $\begin{array}{l}\text { "Quero ter filho com } 35 \\
\text { anos. Também já sei que } \\
\text { quero fazer nutrição. O que } \\
\text { eu gostaria que nunca } \\
\text { mudasse são as lembranças } \\
\text { felizes que eu tive quando } \\
\text { era criança." }\end{array}$ \\
\hline
\end{tabular}


frequência e qualidade das relações. Consequentemente, a solidão foi o sentimento que os acompanhou durante os episódios, uma vez que eles referiram maior isolamento e sensação de desajustamento aos ambientes.

A teoria bioecológica propõe que as características biopsicossociais de um indivíduo podem auxiliar no seu desenvolvimento saudável, mas também interferir de forma prejudicial no seu pleno crescimento psicológico (Bronfenbrenner, 2011). Da mesma forma, no modelo proposto por Nock (2009), há variáveis individuais que parecem oferecer maior risco para o envolvimento em condutas autolesivas. Entre as características apresentadas pelos participantes, destacaram-se a experiência de emoções e pensamentos altamente aversivos (raiva de si, culpa, vergonha, autocriticismo, vazio, desesperança) e aspectos da sexualidade (no caso de Paulo). Entretanto, para que tais características pessoais atuem de forma significativa, é preciso considerar os aspectos relacionais da pessoa no contexto, através do tempo, entendendo que tais dimensões não são um somatório, mas uma interação complexa.

\section{Características da família e rede de apoio percebida (contexto e processos proximais)}

As experiências traumáticas nas relações familiares foram frequentemente mencionadas pelos participantes. Dos quatro participantes, três relataram abusos físicos, psicológicos e sexual sofridos na família nuclear, embora não tenham relacionado tais experiências com as suas autoagressões. Sobre isso, a literatura aponta que a autolesão pode significar uma tentativa desadaptativa de gerenciar as emoções, que pode ter sido aprendida na infância vivenciada em um contexto violento (Peh et al., 2017). Além disso, os resultados demostraram também a insatisfação dos adolescentes diante do manejo familiar com suas emoções, visto que se sentiam invisibilizados, desencorajados e invadidos com frequência - tornando evidente aspectos de um ambiente invalidante.

Assim, se as características da pessoa em desenvolvimento são produto e processo das relações sociais, os processos proximais ajudarão a determinar a forma como o adolescente irá ser e estar no mundo (Bronfenbrenner, 2011). Nesse caso, quando a família nuclear não consegue estabelecer interrelações recíprocas, constantes e regulares para os adolescentes, a família extensa, parte constituinte do mesossistema, pode atuar de forma a amenizar e ressignificar essas relações. O campo "parentes" foi aquele com maior representação de pessoas na rede de apoio dos participantes e apresentou um nível de proximidade maior do que o campo família, indicando que esse é um microssistema com relações protetoras e incentivadoras.

O grupo de pares também demonstrou ser um contexto marcado tanto por relações positivas quanto negativas. Nas entrevistas realizadas com os participantes deste estudo, os pares foram mencionados tanto como fomentadores da autolesão quanto como suporte e 
incentivo à busca por ajuda. O comportamento por contágio é relatado no estudo de Giletta et al. (2015) ao tratarem do papel multiplicador exercido pelo relacionamento entre pares. Esses achados foram também identificados nos dados deste estudo, visto que todos os adolescentes entrevistados conheciam algum amigo próximo ou parente que já havia se autolesionado ou tentado suicídio anteriormente.

Sendo a adolescência um período em que se buscam uma diferenciação do grupo familiar e, ao mesmo tempo, uma maior valorização da rede de amizades, há evidências de que conflitos com os amigos, em conjunto com desamparo familiar, podem aumentar as chances de um envolvimento com condutas autolesivas (Giletta et al., 2015). O bullying é um dos fenômenos que vêm sendo apontados na literatura como um fator precipitante de episódios autolesivos, aumentando os sintomas ansiosos e depressivos (Fisher et al., 2012). Porém, os amigos podem atuar de forma a se apoiarem e protegerem mutuamente, prevenindo novos episódios de lesões autoprovocadas e incentivando a busca por ajuda (Briggs et al., 2017). Neste estudo, o campo dos "amigos" foi o que apresentou maior fator de proximidade entre os participantes no Mapa dos Cinco Campos. Além disso, foi atribuído um sentido positivo para as amizades no que se refere às autolesões, uma vez que os adolescentes buscavam apoio entre os pares e recebiam incentivo para buscar ajuda.

Além das amizades com contato face a face, os participantes também citaram a presença de amigos no ambiente virtual. No entanto, houve algumas divergências quanto ao suporte percebido pela rede formada na internet, visto que, enquanto alguns receberam apoio e acessaram informações positivas para o seu autocuidado, outros relataram ter suscitado mais emoções negativas e comportamentos autodestrutivos nesse meio. Tal ambivalência também é encontrada na literatura, na medida em que a internet pode ser vista como uma ferramenta para normatizar o comportamento autolesivo e disseminar novas formas de autoagressão, mas também como um instrumento para a diminuição do isolamento social, maior expressão emocional e incentivo à busca por auxílio profissional (Briggs et al., 2017).

Por fim, pode-se levantar a hipótese de que o serviço de saúde mental pode ter atuado como um fator protetivo na história dos participantes desta pesquisa, uma vez que não foram identificados em seus relatos aspectos negativos acerca dessa instituição (ver Tabela 1). Todos eles viram o serviço de saúde mental como um lugar positivo e promotor de cuidado, ainda que no Mapa dos Cinco Campos os adolescentes não tenham atribuído alto grau de proximidade com os profissionais nesse campo. Segundo Bronfenbrenner (2011), a inserção do adolescente em um novo contexto permite o movimento das transições ecológicas. Estas possibilitam não só a ampliação do mesossistema da vida do adolescente, como também esse novo ambiente resulta na modificação da sua rede de apoio social e afetiva, além de novas experiências e novas possibilidades de papéis a serem desempenhados (Bronfenbrenner, 2011). O Caps IJ, nesse sentido, surge como uma nova fonte de apoio, permitindo um momen- 
to de reorganização familiar e pessoal dos participantes e oferecendo uma ressignificação de suas experiências.

\section{Perspectivas de futuro (tempo)}

Foram significativas as mudanças identificadas ao longo da história dos participantes. O conceito de cronossistema proposto por Bronfenbrenner (2011) salienta a dimensão temporal em que um indivíduo está inserido, considerando os fatores históricos que se modificam ou permanecem ao longo do seu desenvolvimento. Em termos de macrotempo, pode-se considerar que a doença mental familiar, identificada no histórico de alguns participantes, indica a transgeracionalidade de problemas emocionais ao longo do ciclo da família. Outros estudos a respeito da autolesão também já consideram que ter familiares com algum transtorno mental prévio configura um fator de risco relevante para a suscetibilidade do adolescente ao comportamento de autolesão (Simioni et al., 2018; Tschan et al., 2015). Além disso, a autolesão, apesar de ser um comportamento antigo, vem assumindo o protagonismo entre os jovens nos últimos anos, caracterizando-se como um fenômeno atual que possui também um recorte sociocultural (Favazza, 2009). Favazza (2009) aponta que esse comportamento é, sobretudo, uma forma contemporânea de comportamento de risco e de externalização da dor emocional.

\section{Figura 1}

Modelo integrativo bioecológico do comportamento autolesivo, a partir dos resultados deste estudo, baseado em Nock (2009) e Bronfenbrenner (2011)

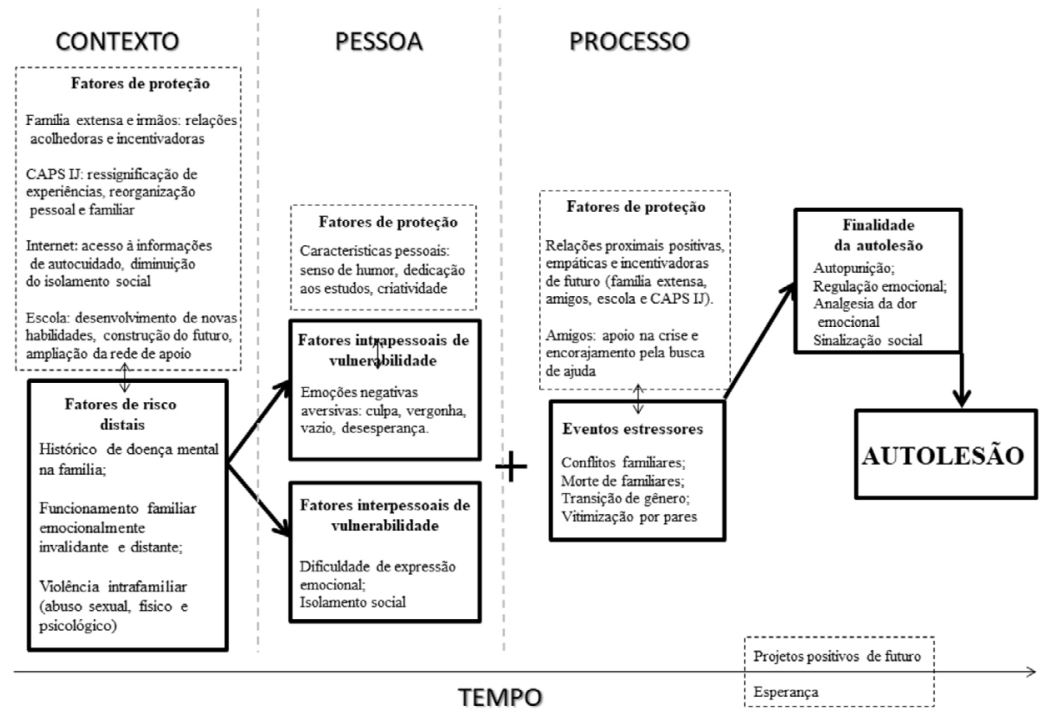


Identificaram-se também eventos estressores na história dos adolescentes que tiveram impacto no seu processo de adoecimento mental de forma particular. A perda de familiares, os conflitos com a família e a mudança de gênero foram algumas das questões mencionadas pelos participantes. Todas essas mudanças envolvem um significado cumulativo às experiências dos adolescentes (Bronfenbrenner, 2011), que podem culminar em estratégias de regulação disfuncionais, como a autolesão.

Quanto ao futuro, observou-se que o desejo positivo de futuro apareceu preservado nos adolescentes dessa pesquisa. Embora tenham sido observadas vulnerabilidades emocionais na dimensão pessoal, o tempo surge como uma forma de reconfigurar a dinâmica dos processos proximais estabelecidos e de possibilitar um novo repertório de habilidades de manejo com os eventos da vida e de interações com o ambiente (Leme et al., 2016).

A partir dos resultados deste estudo, foi organizado um modelo (Figura 1), que leva em conta aspectos da teoria bioecológica (Bronfenbrenner, 2011) e do modelo integrativo de Nock (2009). Nele, foram destacados os principais fatores de risco presentes na história dos adolescentes que parecem ter contribuído para os seus processos autolesivos e os fatores de proteção identificados nos diferentes contextos.

Considerando as relações entre todos os fatores identificados, pode-se compreender de forma mais clara a regulação da experiência afetiva e da situação social vivenciada pelos adolescentes, e como essas variáveis podem estar relacionadas ao comportamento autolesivo. O modelo organizado a partir das informações coletadas sugere a importância de uma abordagem contextualizada, considerando as características dos adolescentes, os contextos de inserção, as mudanças ao longo do tempo e os processos ocorridos. Esses achados podem contribuir para pesquisas e intervenções com adolescentes na escola e no contexto familiar.

O modelo bioecológico permite a investigação dos fenômenos a partir de uma lógica interacionista e integral do desenvolvimento humano. Dessa forma, foi possível avaliar os aspectos individuais dos adolescentes pesquisados em relação às suas redes de apoio nos mais diferentes sistemas e ao longo de um contínuo. Como os principais fatores de risco distais do seu desenvolvimento, identificaram-se o histórico de doença mental familiar, o histórico de violência intrafamiliar pregressa e o ambiente familiar invalidante. Como fatores de risco intrapessoais, observaram-se os sentimentos de culpa, vergonha, desesperança e vazio. Com relação aos fatores de vulnerabilidade interpessoais, identificaram-se o isolamento social e a dificuldade de expressão emocional. Os principais fatores estressores precipitadores das autolesões foram a vitimização por pares, conflitos com a família, transição de gênero e morte de familiares.

Contudo, foi possível observar fatores de proteção em suas histórias individuais, tais como vínculos positivos com parentes e colegas de escola, que lhes fornecem apoio e incentivo; características pessoais de criatividade, senso de humor e dedicação aos estudos; os amigos 
virtuais, que contribuem para diminuir o sentimento de isolamento; o serviço de saúde, que contribui para a reorganização familiar e pessoal dos adolescentes e oferece uma ressignificação de suas experiências; e, ainda, os projetos positivos de futuro, que fornecem um sentimento de esperança. Assim, o conjunto de fatores de proteção identificados favorece o desenvolvimento de um repertório de habilidades para o manejo dos eventos da vida e de interações com o ambiente, podendo amenizar, em alguma medida, o efeito negativo dos fatores de risco.

Entretanto, algumas limitações do estudo podem ser destacadas. O desenho desta pesquisa não permitiu uma análise mais aprofundada do efeito dos fatores de proteção sobre o processo da autolesão e de que forma eles contribuem para amenizar os riscos que levam o adolescente à autolesão. Além disso, a falta de entrevista com os familiares e a falta de informações sobre o histórico escolar impediram uma avaliação mais minuciosa dos processos proximais. Ainda, tendo em vista que a pesquisa foi realizada em um contexto de Caps, com adolescentes em acompanhamento psicológico, pode haver um viés amostral, com a presença de comportamentos autolesivos mais graves do que na população em geral e com maior probabilidade de ter transtornos mentais associados. Quanto ao modelo representado a partir dos dados deste estudo, compreende-se que é necessário validar de forma quantitativa e qualitativa as interações entre fatores de risco e proteção, buscando maior compreensão não apenas sobre os fatores causais desse fenômeno, mas também sobre os fatores mediadores e moderadores.

Para estudos futuros, sugere-se a investigação dos aspectos culturais da autolesão, uma vez que ela se caracteriza como um fenômeno da atualidade. Novos estudos poderão contribuir para que se chegue a um modelo explicativo que avalie o papel mediador e moderador dos fatores de proteção na conduta autolesiva, tornando-o mais integrativo e subsidiando intervenções de prevenção da autolesão. Pesquisas como esta devem estar em constante desenvolvimento, de modo que políticas públicas sejam estruturadas para o fortalecimento do Serviço Único de Saúde (SUS) e sejam aumentados os esforços para a prevenção ao suicídio. É preciso que se investigue a forma como os adolescentes estão sendo vistos e inseridos socialmente e de que forma o seu protagonismo tem sido incentivado ou mitigado. Acredita-se que o fortalecimento de vínculos na adolescência, sejam eles familiares, comunitários ou entre pares, possa ser um caminho possível para atenuar o sofrimento emocional, diminuir os comportamentos de risco e aumentar suas possibilidades de enfrentamento ao estresse. 


\section{Referências}

Ammerman, B. A., Jacobucci, R., Turner, B. J., Dixon-Gordon, K. L., \& McCloskey, M. S. (2019). Quantifying the importance of lifetime frequency versus number of methods in conceptualizing nonsuicidal self-injury severity. Psychology of Violence, 10(4), 442-451. http://dx.doi. org/10.1037/viooooo263

Bardin, L. (2011). Análise de conteúdo. Edições 70.

Briggs, S., Slater, T., \& Bowley, J. (2017). Practitioners' experiences of adolescent suicidal behaviour in peer groups. Journal of Psychiatric and Mental Health Nursing, 24(5), 293-301. https://doi. org/10.1111/jpm.12388

Bronfenbrenner, U. (2011). Bioecologia do desenvolvimento humano: Tornando os seres humanos mais humanos (Carvalho-Barreto, A., trad.). Artmed.

Calati, R., Ferrari, C., Brittner, M., Oasi, O., Olié, E., Carvalho, A. F., \& Courtet, P. (2019). Suicidal thoughts and behaviors and social isolation: A narrative review of the literature. Journal of Affective Disorders, 245, 653-667. https://doi.org/10.1016/j.jad.2018.11.022

Crowell, S. E., Baucom, B. R., McCauley, E., Potapova, N. V., Fitelson, M., Barth, H., Smith, C. J., \& Beauchaine, T. P. (2013). Mechanisms of contextual risk for adolescent self-injury: Invalidation and conflict escalation in mother-child interactions. Journal of Clinical Child \& Adolescent Psychology, 42(4), 467-480. https://doi.org/10.1080/15374416.2013.785360

Favazza, A. R. (2009). A cultural understanding of nonsuicidal self-injury. In M. K. Nock (Ed.), Understanding nonsuicidal self-injury: Origins, assessment, and treatment (pp. 19-35). American Psychological Association. https://doi.org/10.1037/11875-002

Fisher, H. L., Moffitt, T. E., Houts, R. M., Belsky, D. W., Arseneault, L., \& Caspi, A. (2012). Bullying victimisation and risk of self harm in early adolescence: Longitudinal cohort study. BMJ, 344, e2683. https://doi.org/10.1136/bmj.e2683

Fonseca, P. H. N. D., Silva, A. C., Araújo, L. M. C. D., \& Botti, N. C. L. (2018). Autolesão sem intenção suicida entre adolescentes. Arquivos Brasileiros de Psicologia, 70(3), 246-258. http://pepsic.bvsalud.org/scielo.php?script=sci_arttext\&pid=S1809-52672018000300017

Giletta, M., Prinstein, M. J., Abela, J. R., Gibb, B. E., Barrocas, A. L., \& Hankin, B. L. (2015). Trajectories of suicide ideation and nonsuicidal self-injury among adolescents in mainland China: Peer predictors, joint development, and risk for suicide attempts. Journal of Consulting and Clinical Psychology, 83(2), 265-279. https://doi.org/10.1037/a0038652

Hoppe, M. (1998). Redes de apoio social e afetivo de crianças em situação de risco. [Dissertação de mestrado não publicada]. Universidade Federal do Rio Grande do Sul. Porto Alegre, RS.

Leme, V. B. R., Del Prette, Z. A. P., Koller S. H., \& Del Prette, A. (2016). Habilidades sociais e o modelo bioecológico do desenvolvimento humano: Análise e perspectivas. Psicologia \& Sociedade, 28(1), 181-193. https://dx.doi.org/10.1590/1807-03102015aopoo1

Nock, M. K. (2009). Why do people hurt themselves? New insights into the nature and functions of self-injury. Current Directions in Psychological Science, 18(2), 78-83. https://doi. org/10.1111/j.1467-8721.2009.01613.x 
Peh, C. X., Shahwan, S., Fauziana, R., Mahesh, M. V., Sambasivam, R., Zhang, Y., Ong, S. H., Chong, S. A., \& Subramaniam, M. (2017). Emotion dysregulation as a mechanism linking child maltreatment exposure and self-harm behaviors in adolescents. Child Abuse \& Neglect, 67, 383-390. https://doi.org/10.1016/j.chiabu.2017.03.013

Simioni, A. R., Pan, P. M., Gadelha, A., Manfro, G. G., Mari, J. J., Miguel, E. C., Rohde, L. A., \& Salum, G. A. (2018). Prevalence, clinical correlates and maternal psychopathology of deliberate self-harm in children and early adolescents: Results from a large community study. Brazilian Journal of Psychiatry, 4O(1), 48-55. https://dx.doi.org/10.1590/1516-4446-2016-2124

Tomé, G., Camacho, I., Matos, M. G., \& Simões, C. (2015). Influência da família e amigos no bem-estar e comportamentos de risco: Modelo explicativo. Psicologia, Saúde \& Doenças, 16 (1), 23-34. http://dx.doi.org/10.15309/15psd160104

Tschan, T., Schmid, M., \& In-Albon, T. (2015). Parenting behavior in families of female adolescents with nonsuicidal self-injury in comparison to a clinical and a nonclinical control group. Child and Adolescent Psychiatry and Mental Health, 9(1), 17. https://doi.org/10.1186/s13034-015-0051-x

Turecki, G., \& Brent, D. A. (2016). Suicide and suicidal behaviour. The Lancet, 387(10024), 1227-1239. https://doi.org/10.1016/S0140-6736(15)00234-2

Yin, R. K. (2005). Estudo de caso: Planejamento e métodos. Bookman.

Zappe, J. G., \& Dell'Aglio, D. D. (2016). Variáveis pessoais e contextuais associadas a comportamentos de risco em adolescentes. Jornal Brasileiro de Psiquiatria, 65(1), 44-52. https://doi. org/10.1590/0047-2085000000102

\section{EQUIPE EDITORIAL}

\section{Editora-chefe}

Cristiane Silvestre de Paula

\section{Editores associados}

Alessandra Gotuzo Seabra

Ana Alexandra Caldas Osório

Luiz Renato Rodrigues Carreiro

Maria Cristina Triguero

Veloz Teixeira

\section{Editores de seção \\ "Avaliação Psicológica"}

Alexandre Serpa

André Luiz de Carvalho Braule Pinto

Luiz Renato Rodrigues Carreiro Vera Lúcia Esteves Mateus

\section{"Psicologia e Educação"}

Alessandra Gotuzo Seabra

Carlo Schmidt

Regina Basso Zanon

\author{
"Psicologia Social e Saúde das \\ Populações" \\ Enzo Banti Bissoli \\ Marina Xavier Carpena
}

"Psicologia Clínica"

Carolina Andrea Ziebold Jorquera

Julia Garcia Durand

Natalia Becker

"Desenvolvimento Humano"
Maria Cristina Triguero
Veloz Teixeira
Rosane Lowenthal
Suporte técnico
Maria Fernanda Liuti
Bento da Silva
Camila Fragoso Ribeiro

PRODUÇÃO EDITORIAL

Coordenação editorial

Ana Claudia de Mauro

\section{Estagiários editoriais}

Júlia Lins Reis

Pietro Menezes

Élcio Carvalho

\section{Preparação de originais}

Carlos Villarruel

\section{Revisão}

Vera Ayres

\section{Diagramação}

Acqua Estúdio Gráfico 